\title{
Total Synthesis of Aureothin and
}<smiles>COc1oc(C=O)c(C)c(=O)c1C</smiles>

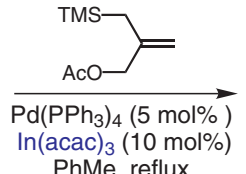
$\mathrm{PhMe}$, reflux

$93 \%$<smiles>C=C1COC(c2oc(OC)c(C)c(=O)c2C)C1</smiles>

B

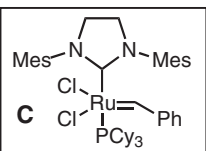

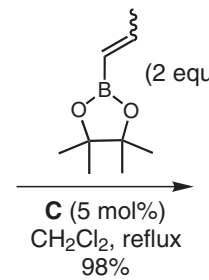

$98 \%$<smiles>COc1oc(C2CC(=CB3OC(C)(C)C(C)(C)O3)CO2)c(C)c(=O)c1C</smiles>
$E: Z=1: 1.2$

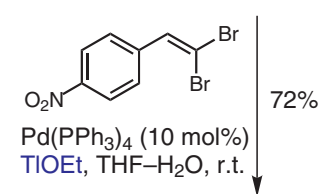<smiles>COc1oc(C2(F)C/C(=C\C(Br)=C\c3ccc([N+](=O)[O-])cc3)CO2)c(C)c(=O)c1C</smiles>

E

Aureothin $\left(\mathrm{R}=\mathrm{NO}_{2}\right)$

$\mathrm{N}$-Acetylaureothamine $(\mathrm{R}=\mathrm{NHAc})$

Significance: Aureothin is an unusual nitroaryl metabolite of Streptomyces netropis. It has antitumor, antifungal and pesticidal activity. N-Acetylaureothamine is active against Helicobacter pylori, the cause of chronic gastritis.
Comment: A remarkably short and efficient synthesis of $( \pm$ )-Aureothin (23\% overall) features three $\mathrm{Pd}$-catalyzed reactions and a Ru-catalyzed cross metathesis. The precipice of failure in the three Pd-catalyzed reactions was avoided by deft use of additives: In(acac) $)_{3}$ for the [3+2] cycloaddition leading to tetrahydrofuran B; TIOEt for the Suzuki cross-coupling to form $\mathbf{E}$; the highly hindered ligand $t-\mathrm{Bu}_{3} \mathrm{P}$ for the final Negishi cross-coupling. 